suppressive treatment he was on for ulcerative colitis was a significant risk factor for deepseated fungal infection and, in retrospect, the diagnosis could perhaps have been suspected earlier.

Prompt treatment and early diagnosis is critical, but as this case illustrates, it can be very difficult. Apart from oral candidiasis, there was nothing to raise the suspicion of a fungal peritonitis. Without the third laparotomy, the diagnosis would not have been considered until Candida was demonstrated from peripheral sites seven days later.

Serodiagnosis of candidal infection can be difficult. Candida antigen detection is specific and can help distinguish colonised from systemically infected patients, but sensitivity can be low. ${ }^{4}$ Confirmation of systemic candidiasis requires isolation from blood cultures or an otherwise sterile site except urine, or histological evidence of yeast or mycelia forms in tissues from an 'at risk' patient. ${ }^{5}$ which can take time. Amphotericin B is recommended for the treatment of deep Candida infections, with fluconazole being a second-line treatment. ${ }^{5}$ Conventional amphotericin B is nephrotoxic and should not be administered in a dosage exceeding $1.5 \mathrm{mg}$ / $\mathrm{kg} /$ day. Liposomal amphotericin has a significantly shorter infusion time than conventional amphotericin B and is reported as giving a rise to less systemic toxicity and renal impairment, ${ }^{6}$ enabling the administration of a much higher dosage than with conventional amphotericin. Amphotericin B causes hypokalaemia and although liposomal amphotericin $\mathbf{B}$ has been reported as causing hypokalaemia in up to $18 \%$ of cases, our patient tolerated the liposomal amphotericin well, with rapid clinical improvement.
The possibility of candidal peritonitis, although very rare, should be considered in any patient potentially at risk. Empirica antifungal treatment should be considered pending the results of other investigations such as serology and peripheral cultures. We suggest that clinicians consider liposomal amphotericin as a useful alternative to conventional amphotericin $B$ in these patients.

SUI YIN NG MARINA MORGAN Mayday Hospital

Thornton Heath Surrey CR4 7YE, UK

We would like to thank Mr AJ Knox and Dr TJ Clarke for their permission to report this case.

1 Calandra T, Bille J, Schneider R, Mossiman F, Francioli P. Clinical significance of Candida isolated from peritoneum in surgical patients. Lancet 1989; 2: 1437-40.

2 Rantala A, Lehtonen OP, Kuttila K, Havia T, Ninikoski J. Diagnostic factors for postoperative cindidosis in abdominal surgery. Ann Chirurg Gynaecol 1991; 80: 323-8. 3 Murugasu B, Conley SB, Lemire JM, Portman
RJ. Fungal peritonitis in children treated with RJ. Fungal peritonitis in children treated with peritoneal dialysis and gastron

4 Matthews RC. Early diagnosis of systemic candidal infection. $f$ Antimicrob Chemother 1993; 31: 809-12.

5 British Society for Antimicrobial Chemotherapy Working Party. Management of deep Candida infection in surgical and intensive care unit patients. Intens Care Med 1994; 20: 522-8.

6 Collette N, Van Der Auwera P, Meunier F, Lambert C, Sculier IP, Coune A. Tissue distribution and bioactivity of amphotericin $B$ administered in liposomes to cancer patients. Antimicrob Chemother 1991; 27: 535-48.

\section{Follow-up of mycoplasma pneumonia}

Sir,

I was interested to read the learning points tabled in Dr Shah's useful paper ${ }^{1}$ on adult respiratory distress syndrome due to mycoplasma pneumonia. They did not mention follow-up of this acute condition.

In 1973 my late wife developed respiratory distress shown to be due to mycoplasma pneumonia. It cleared rapidly on treatment and three months later a chest $\mathrm{X}$-ray was normal. A year later another severe respiratory infection led to a further chest X-ray and this showed widespread deposits from primary adenocarcinoma of the lung. This, of course, is anecdotal evidence, but I think you will understand why I personally feel that such a respiratory infection occurring in a previously healthy subject should be followed up very carefully for at least a year or two after the event.

JOHN HOPEWELI

The Old Vicarage, Langrish, Petersfield, Hampshire GU32 1QY, UK

1 Shah DC, Muthiah MM. Adult respiratory distress syndrome due to mycoplasma pneumonia. Postgrad Med $\mathcal{F}$ 1996; 72: 239-40. 